\title{
Erratum
}

\section{Femoroacetabular Impingement}

\section{Do Outcomes Reliably Improve with Surgical Dislocations?}

\author{
Matt L. Graves MD, Jeff W. Mast MD
}

\section{Erratum to: Clin Orthop Relat Res DOI 10.1007/s11999-008-0648-y}

The affiliation of second author of this article (J. W. Mast) was incorrectly identified as:

Department of Orthopaedic Surgery, University of Nevada-Reno Medical Center, Reno, NV, USA
The correct affiliation for Dr. Mast is as follows:

Department of Surgery, Northern Nevada Medical Center, Sparks, NV, USA

The authors regret this error.

The online version of the original article can be found under doi:10.1007/s11999-008-0648-y.

M. L. Graves $(\bowtie)$

Department of Orthopaedic Surgery and Rehabilitation,

University of Mississippi Medical Center, 2500 North State

Street, Jackson, MS 39216, USA

e-mail: mattgraves1@gmail.com

J. W. Mast

Department of Surgery, Northern Nevada Medical Center,

Sparks, NV, USA 